\title{
KAJIAN IKONOGRAFIS \\ BAHASA RUPA UANG KERTAS INDONESIA MASA REVOLUSI
}

\author{
Baskoro Suryo Banindro \\ Dosen Program Studi Disain Komunikasi Visual \\ Jurusan Disain FSR ISI Yogyakarta \\ Email: banindro@yahoo.com
}

\begin{abstract}
Bank note as a medium for visual communication, in it loaded with aesthetic values associated with beauty problems. Composed ofletters, pictures, colors and unique printing techniques. Paper money as a sign of payment, in addition to having intrinsic value in the form of nominal value, has also the function of signification, that is a function where bookmarks (signifier), which is concrete as a medium of exchange, laden with abstract concepts or meanings commonly referred to as marker (signified) in form of text and images. In the image of paper money, which is poured visual expression can reflect ideas, concepts or symbolic meanings related to hegemony, legitimacy, ideology, the existence, sovereignty of both states and rulers.

Oeang Repoeblik Indonesia (ORI), is the first legitimate currency owned by the Republic of Indonesia after independence. Since printed in December 1945 to December 1949, in addition to pictorial inzet Sukarno, the Indonesian tradition of cultural objects more dominate and become the main image. Departure from this phenomenon, need to be studied in greater depth and comprehensive visual and symbolic aspects of paper money during the ORI physical revolution. By looking at the artifacts of the images on paper money ORI 1945 - 1949, built on the revolutionary period, besides the symbolic language of art is a form of symbolic expression to foster community spirit of nationalism and patriotism of the newly independent Indonesia, as well as communicating, showing identity, reflecting the spirit and the factual circumstances of his time.
\end{abstract}

Keywords:Visual language, currency of Indonesian Republic (ORI), tradition object drawing, epoch reflections

\section{Pendahuluan}

Uang kertas sebagai salah satu media komunikasi visual sarat dengan nilai estetik yang berhubungan dengan masalah keindahan. Estetika bahasa rupa tersusun atas huruf, gambar, warna serta teknik cetak yang khas. Hasil karya seorang pencipta tidak akan pernah menjadi sebuah produk seni apabila karya tersebut tidak memiliki "bentuk estetik" yang bermakna. (Damianus, 2005: 212) Bentuk bermakna yang dimaksud ialah relasi dan kombinasi dari garis-garis dan warnawarna yang secara harmonis membangun sebuah rupa. (Malvin, 1973: 252)

Sebagai alat transaksi, uang kertas merupakan produk kebudayaan. Tentunya tidak lepas dari fenomena kebudayaan yang meliputi nilai-nilai spiritual, sistem ekonomi dan sosial. Uang kertas dalam perjalanannya lahir dari proses panjang, dikenal pertama di Cina sejak dinasti Wu Ti pada abad ke 2 sebelum Masehi dan kemudian dikenal luas sebagai alat pembayaran dalam berdagang pada abad ke-7 oleh dinasti Tang. (Krisnadi, 2007: 11) Uang kertas sebagai tanda pembayaran mempunyai nilai intrinsik dan funghsi signifikasi. Nilai intrinsik diwujudkan dalam bentuk value nominal, sedangkan signifikasi berfungsi sebagai penanda (signifier) yang bersifat kongkret sebagai alat tukar, dimuati dengan konsep-konsep abstrak atau makna yang umum disebut petanda (signified) dalam bentuk teks dan gambar. Dilain pihak manusia senantiasa mengekspresikan dan memancarkan pengalamannya dalam bentuk ujud atau rupa. Dalam gambar uang kertas, ekspresi visual yang dituangkanpun dapat mencerminkan ide, konsep atau makna simbolik terkait hegemoni, legitimasi, 
ideologi, eksistensi, kedaulatan baik negara maupun penguasa.

\section{Hasil Penelitian}

Uang kertas Indonesia merupakan bagian dari sejarah revolusi bangsa (Sartono Kartodirdjo, guru besar sejarah pada Universitas Gajahmada Yogyakarta, di dalam majalah Prisma Agustus 1981 no. 8, halaman 3,mengatakan bahwa Sejarah Revolusi Indonesia bukan saja fakta-fakta tentang peristiwaperistiwanya, melainkan bagaimana pandangan ataupun gambaran mengenai peristiwa-peristiwa itu. .......... Revolusi kita merupakan masa pergolakan (bahasa Jawa gegeran) yang ditandai oleh ,srobotan', 'gedoran', 'pendaulatan', di samping sebagai masa perjuangan"..) Sementara Pemerintah Republik Indonesia (RI) belum memiliki mata uang yang dibuat oleh negara dan dikeluarkan secara resmi, maka melalui maklumat Presiden No. 1/10 tanggal 3 Oktober 1945, mengijinkan sementara berlaku dan beredarnya 3 (tiga) macam uang, masing-masing yang dikeluarkan oleh de Javasche Bank, uang kolonial Belanda dan uang pendudukan Jepang. (Fitrianti, 2008: 11) Uang Republik Indonesia yang dimaksud ialah Oeang Repoeblik Indonesia (ORI), yang merupakan mata uang sah pertama yang dimiliki Republik Indonesia setelah merdeka. ORI secara sah ditetapkan sejak 30 Oktober 1946, mulai pukul 00.00 dan berlaku di seluruh wilayah bekas jajahan Belanda atau Netherland Indie. (Wiratsongko, 1990: 12)

Sejak dicetak pada bulan Desember 1945 hingga bulan Desember 1949, pemerintah Republik Indonesia (RI) telah menerbitkan mata uang kertas ORI sebanyak 5 (lima) seri dengan jumlah emisi sebanyak 26 (dua puluh enam) satuan, mulai dari nominal terendah 1 (satu) sen hingga satuan tertinggi senilai 600 (enam ratus) rupiah. Visualisasi ORI seri I (pertama) hingga seri V (kelima), selain bergambar inzet Sukarno (Presiden RI pertama), objek budaya tradisi Indonesia lebih banyak mendominasi dan dijadikan gambar utama pada tiap lembaran uang kertas ORI, misalnya seri senjata tradisional divisualkan dengan objek seperti keris, badik, parang, seri pertanian bergambar petani sedang panen padi, tembakau, kebun tebu dan seri mata pencaharian divisualkan dengan objek orang sedang menenun, menyadap karet, serta pande besi. Melalui visualitas pada ORI inilah secara simbolis bahasa rupa mengomunikasikan sekaligus menunjukkan identitasnya, bahwa ORI tidak sebatas alat tukar namun mampu menjadi media pembentukan komunitas sebagai bangsa menjadi nyata.

Dalam pandangan Panofsky (1979: 28 30) ikonografis merupakan mekanisme untuk mengidentifikasi makna terhadap aspek representasi, baik metafora maupun alegori, yaitu cerita yang dikisahkan dalam bentuk lambanglambang, dengan melihat hubungan antara motif sebuah karya seni dengan unsur, konsep atau makna yang terkait dengan peristiwa yang diangkat oleh sebuah gambar. Ada tiga tahapan dalam menganalisisnya, yaitu (1) Tahap praikonografis ialah langkah atau tahap awal atau bahasan primer, dalam mendeskripsikan ciri-ciri visual yang tampak dari sebuah objek amatan. Pokok bahasan primer atau alami, dibagi lagi ke dalam faktual dan ekspresional. Ini dipahami dengan mengidentifikasi-kan bentuk murni yaitu konfigurasi tertentu dari garis dan warna, atau material sebagai representasi atas objek alami dengan mengidentifikasikan hubungan bersamaan mereka sebagai peristiwa-peristiwa dan dengan merasakan kualitas ekspresional itu sebagai karakter atau atmosfer yang kemudian dikenali sebagai pembawa makna primer atau alami dari motif artistik. (2) Tahap ikonografis yaitu sebagai tahap untuk mengidentifikasi makna sekunder terhadap aspek representasi, baik metafora maupun alegori, yaitu cerita yang dikisahkan dalam bentuk lambang-lambang, dengan melihat hubungan antara motif sebuah karya seni dengan unsur, konsep atau makna yang terkait dengan peristiwa yang diangkat oleh sebuah gambar.

Motif yang juga dikenali sebagai pembawa makna konvensional dapat disebut gambar atau gambaran, dan kombinasi dari gambar-gambar adalah apa yang disebut ahli teori seni kuno sebagai cerita dan alegori (invenzioni). (3) Tahap ikonologis yaitu suatu tahapan tingkat lanjut untuk melakukan interpretasi secara komprehensif makna intrinsik atau isi. Ini 
dipahami dengan menegaskan prinsip dasar yang memaparkan atitude dasar dari suatu bangsa, zaman, kelas, persuasi filosofis atau religius yang dikualifikasikan oleh satu kepribadian dan dipadatkan ke dalam satu karya. Analisisnya dilakukan dengan mempertimbangkan seluruh aspek representasi kaitannya dengan pemahaman sejarah, ideologi dan kondisi psikologis pencipta karya seni.

Salah satu kelebihan metode ini ialah kemampuannya dalam membongkar tanda yang dipakai untuk memahami secara kritis bahasa rupa yang terselubung serta ideologi yang direproduksi oleh satu sistem pertandaan . Sebagai studi kasus, maka kajian tentang simbolisme uang kertas ORI masa revolusi 1945 - 1949, dapat diuraikan dengan matrik praikonigrafis, ikonografis, dan ikonologis sebagai berikut: perwujudan bahasa rupa dari segi teknik dapat berbentuk ekspresif, geometris, digayakan, deskriptif. Dari aspek pemaknaan dapat berwujud estetik, simbolik, dan "bahasa rupa "itu sendiri (Tabrani, 2005: 95).

Uang kertas sebagai bagian dari numismatik (Sjamsudin, 2007: 240) mempunyai fungs penting dalam membantu penelitian dan penulisan sejarah.

Menurut Barzun \& Graff (1970: 148) dalam bukunya The Modern Researcher dikatakan bahwa mata uang sebagai sebuah karya seni merupakan bagian dari sumber sejarah yang dikelompokkan dalam klasifikasi catatan-catatan atau record pelantar fakta yang direncanakan. Data yang diperoleh dari olah-alih material berupa gambar atau figur, reproduksi cetak, baik berupa ornamen, grafis maupun fotografi pada uang

\begin{tabular}{|c|c|c|c|}
\hline & Praikonografis & Ikonografis & Ikonologis \\
\hline Kegiatan & $\begin{array}{l}\text { Identifikasi formal } \\
\text { objek }\end{array}$ & Analisis objek & Intepretasi objek \\
\hline Objek & $\begin{array}{l}\text { Pengamatan visual } \\
\text { terhadap objek } \\
\text { yang paling utama, } \\
\text { fakta fisik, material } \\
\text { dan ekspresi terkait } \\
\text { dengan motif } \\
\text { artistik }\end{array}$ & $\begin{array}{l}\text { Pengamatan terhadap } \\
\text { objek utama terkait } \\
\text { dengan citraan, cerita } \\
\text { dan alegoris }\end{array}$ & $\begin{array}{l}\text { Memberikan makna } \\
\text { intrinsik atas simbol } \\
\text { yang ada }\end{array}$ \\
\hline $\begin{array}{l}\text { Bahan } \\
\text { Kajian }\end{array}$ & $\begin{array}{l}\text { Pengalaman } \\
\text { praktis terhadap } \\
\text { objek dan event }\end{array}$ & $\begin{array}{l}\text { Pengetahuan atas } \\
\text { dasar literatur, baik } \\
\text { mengenai tema dan } \\
\text { konsep }\end{array}$ & $\begin{array}{l}\text { Esensi terhadap } \\
\text { situasi,tendensi, } \\
\text { kondisi psikologis } \\
\text { artis }\end{array}$ \\
\hline $\begin{array}{l}\text { Koreksi } \\
\text { atas } \\
\text { amatan }\end{array}$ & $\begin{array}{l}\text { Sejarah gaya: } \\
\text { objek dan event }\end{array}$ & $\begin{array}{l}\text { Sejarah tipe: tema dan } \\
\text { konsep }\end{array}$ & $\begin{array}{l}\text { Sejarah budaya } \\
\text { yang menyertai: } \\
\text { simptom atas } \\
\text { simbol yang ada. }\end{array}$ \\
\hline
\end{tabular}

Tabel 1. Alur konseptual Ikonografis

Bahasa rupa merujuk pada seluruh hal yang berhubungan dengan "rupa" suatu gambar. Adapun sumber gambar yang dimaksud ialah sesuatu yang tampak pada suatu bidang yang relatif datar: sketsa, gambar, lukisan, foto, karya grafis, imajinsi, kenangan, kata dsb. (Soegeng Toekio, 2007: 15) Bahasa rupa hadir dalam perwujudan gambar yang representatif, bukan abstrak dan geometris, gambar yang mewakili aslinya sehingga dapat dikenali. Dalam kertas merupakan sumber data yang akurat dan bukti sejarah yang tidak ternilai. (Garraghan, 1957:22)

Sebagai karya rancang grafis, uang kertas tersusun atas perwujudan rupa: teks dan gambar, dengan bahasa gambar seseorang dapat menafsirkan berdasarkan tanda dan makna yang bersifat universal, (Abdullah Noer, 2003: 43) di dalamnya terdapat elemen rupa berupa unsur rupa yaitu: garis, warna, bentuk, huruf, dan komposisi. 
Terkait dengan fungsi seni sebagai wadah untuk menyampaikan sebuah ideologi, Wolff (1993: 63) menyebut seniman dan karyanya sebagai 'agen ideologi'. Baik secara tekstual maupun kontekstual, yang menjadikan media untuk mengekspresikan pandangan dan kepercayaan sebuah kelompok, bisa aspek politik, sosial, dan gagasan/pemikiran lainnya dalam sebuah medium artistik.

Disain grafis merupakan salah satu manifestasi kebudayaan dalam bentuk produk yang berlaku pada kurun waktu tertentu. Pada dasarnya mendisain dalam pandangan Widagdo (1993: 32) adalah sebuah proses yang melibatkan alat untuk memproses (membuat informasi) dan subjek yang diproses (masalah), dan pemroses (disainer).

Dalam proses perancangan dan untuk mewujudkan karya diperlukan pemikiran yang logis, intuitif - empirik dan tentunya kontemplasi sang perancang. (Widagdo, 1993: 33) Dalam sejarah peradaban masalah mengung-kapkan bentuk dan konsep estetik inilah yang biasa dijadikan tanda dan ciri zaman (zeitgeist). (Widagdo, 1993: 41) merdeka dan berdaulat. (Wardhana, 2009: 9) ORI pernah dicetak dibeberapa tempat, antara lain: Jakarta, Yogyakarta, Surakarta dan Malang.

Pada saat dibuat di Jakarta, ORI dibuat oleh perancang uang (Setiap uang kertas yang dikeluarkan tentu memiliki perancang atau pelukisnya. Biasanya para perancang atau pelukis uang tersebut dituliskan di bagian bawah berupa nama dan singkatan DEL, yang artinya Delinavit atau pelukis uang.) Abdulsalam dan Soerono, (Wiratsongko, 1990: 4) Proses cetak dilakukan di percetakan negara "Salemba" Jakarta yang di zaman Belanda bernama "Lands Drukkerij". Ketika ibukota hijrah ke Yogyakarta, pencetakan uang dilakukan di gedung percetakan negara "Gondo Rumeksa" di Kidul Loji, Gondomanan (Dahana, 2002: 84) Delinavit pada uang kertas ORI seri Yogyakarta adalah Dibyo Pramudjo dan Umar. (Hajarini: 112) ORI seri Yogyakarta yang lain dicetak di "Canisius Drukkerij" (Katalog 75 Tahun Kanisius, 1997: 11) Di wilayah Jawa Timur uang ORI di buat di percetakan eks percetakan uang Belanda Nederlands Indische Metaalwaren en Emballage Fabrieken (NIMEF) di Kendalpayak, Malang. (Widarti, 1984: 32)

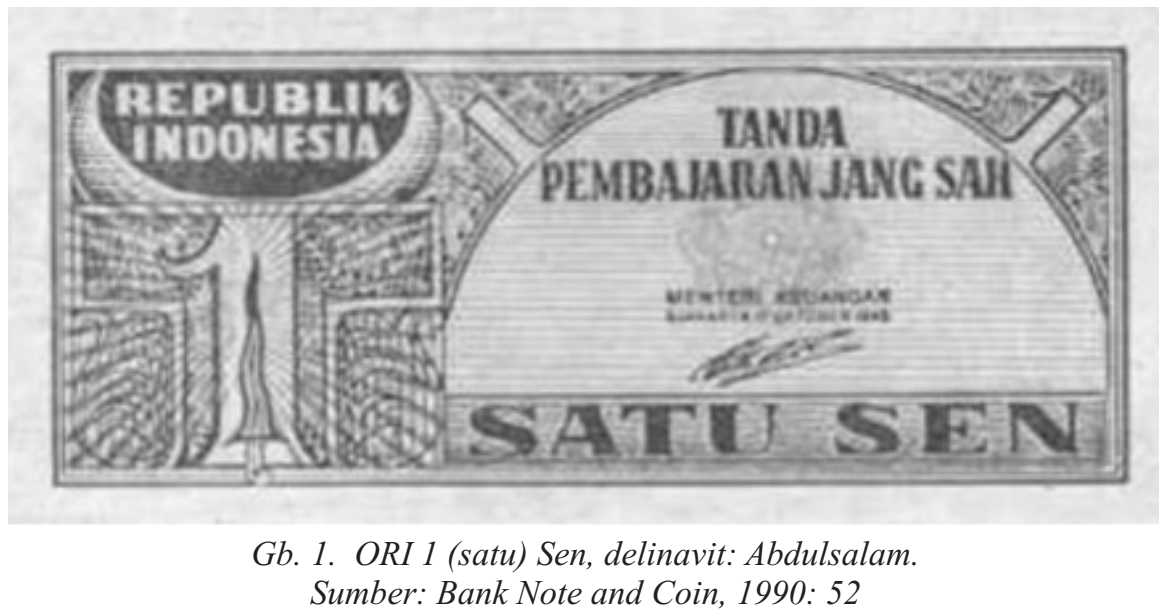

\section{Pembahasan}

Gagasan untuk mencetak uang pertama kali dicetuskan oleh Syafrudin Prawiranegara pada saat diadakan pertemuan di kantor Wakil Presiden antara bulan September dan Oktober 1945. (Oey dalam Nurhajarini, 1999: 33) Pada pertemuan tersebut Moh. Hatta merespon dan mengemukakan tentang perlunya mengeluarkan uang baru sebagai salah satu atribut negara
Gambar tanduk dan keris merupakan representasi alegoris memaparkan atitud dasar zamannya yang diekspresikan dalam bentuk artefak budaya Indonesia sebagai penanda. Pada mata uang 1 (satu) sen, gambar keris ligan luk lima yang berpendar cahaya atau aura bergambar pamor di dalamnya, mengasosiasi-kan keris yang berkharisma, keris sakti dan magis. Keris adalah budaya asli indonesia (Harsrinuksmo, 2004: 13) 
keris luk 5 (lima) dikenal pula dengan nama dapur pandawa, yang melambangkan agar pemiliknya selalu bersikap "diplomatis" dan memiliki watak agung seperti ksatria "Pandawa Lima". (Adinagoro, 2009:17) Terbukti "uang putih" ORI 1 (satu) sen di masa revolusi, menjadi alat untuk melawan uang "merah" NICA Belanda 1 (satu) gulden. Petani dan pegawai di daerah pendudukan, lebih senang menerima dan membelanjakan uang ORI yang sederhana buatannya serta menolak uang NICA. (Kahin: 1999: 502) Setidaknya fakta tersebut merupakan salah satu upaya "diplomatis" yang muncul atas sugesti gambar uang ORI. Sebagai budaya asli Indonesia, keris merupakan simbol kepribadian bangsa, yang mempertebal harga diri dan kebanggaan nasional serta memperkokoh jiwa kesatuan nasional. (Wibawa, Prasida, 2008:8) Kedudukan keris dalam sejarah bangsa, tidak dapat dipungkiri lagi, dalam ceritera babad maupun sejarah modern, keris banyak berfungsi sebagai objek sejarah, bahkan keris kadangkadang dapat menjadi benda penentu sejarah. (Surono, 1979, 2) mengkiaskan para pejuang Indonesia di front Surabaya. Melalui cuplikan transkrip orasi pidato yang heroik pada tanggal 10 Nopember 1945 , Bung Tomo membakar semangat para pejuang dengan sebutan banteng:

"Selama banteng-banteng Indonesia masih mempoenjai darah merah jang dapat membikin setjarik kain poetih mendjadi merah \& poetih, maka selama itoe tidak akan kita maoe menjerah kepada siapapoen djoega!"

Pada ORI 250 (dua ratus lima puluh) Rupiah, sosok Sukarno digambarkan mengenakan atribut kemiliteran. Dalam kesempatan lain sesudah revolusi berakhir, Soekarno mengutarakan kepada Cindy Adams (1963: 81) mengapa ia harus mengenakan seragam militer:

"Look here, I am a mass psychologist. I have other suits. I prefer uniforms for every public appearance because I know downtrodden people delight to see their President crisply tailored. An Indonesian leader must be a

Hal tersebut menjadikan dirinya mendapat julukan sebagai salah seorang bapak bangsa (one of nation's founding fathers). Sebagai

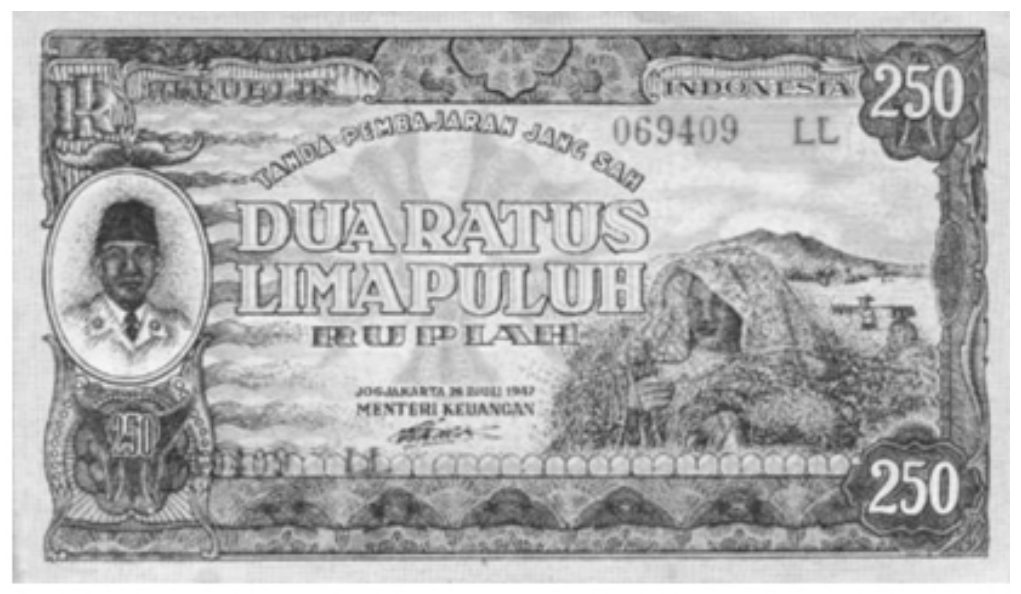

Gb. 2. ORI 250 (dua ratus lima puluh) Rupiah, delinavit: Dibyo Pramudjo. Sumber: Bank Note and Coin, 1990: 61

Kepala banteng dibuat dengan gambar tanduk saja, menunjukkan pemahaman dari perancang uang, bahwa tanduk adalah bagian paling mengesankan dan senjata utama dari seekor banteng. Banteng Jawa merupakan simbol perlawanan terhadap penjajah di masa revolusi. Banteng adalah istilah yang digunakan oleh Bung Tomo untuk menyebut, mengidentifikasi ataupun delinavit uang ORI 250 (dua ratus lima puluh) rupiah, memahami perannya sebagai "agen ideologi". Jiwa artistiknya menangkap budaya tradisi Yogyakarta, dan menerjemahkannya dalam bahasa rupa, merupakan suatu tindakan yang oleh Wolff dikatakan sebagai sikap ideologis dalam memujudkan gagasan dan kepercayaan yang telah diberikan kepadanya, Pemikiran dan kesadaran 


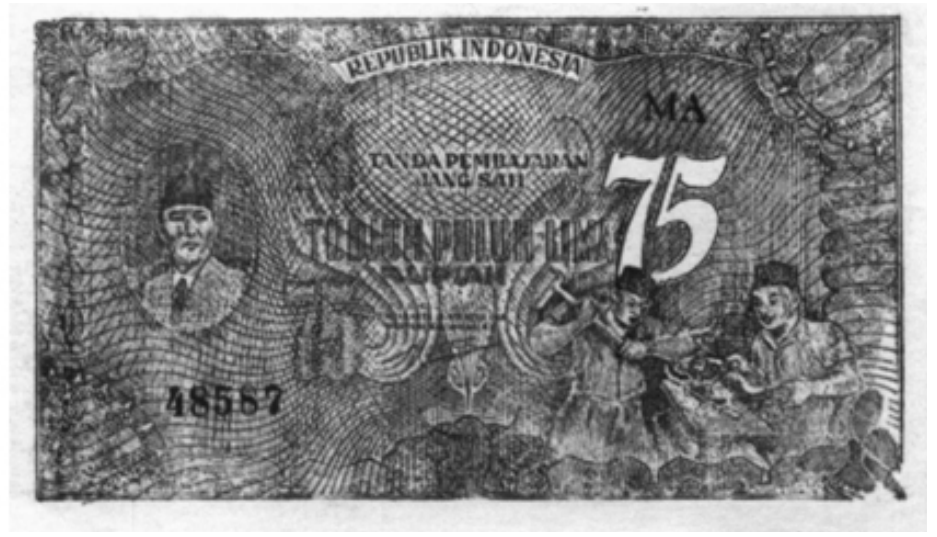

Gb. 3. Uang ORI 75 (Tujuh Puluh Lima) Rupiah).

Delinavit: Dibyo Pramudjo, Sumber: Bank Note and Coin, 1990: 62

yang berasal dari aktivitas-aktivitas materiil dan interaksi sosialnya, direfleksikan untuk menandai simbol budaya tradisi Indonesia, suatu pemikiran ideologis yang menurut Raymond Williams diartikan sebagai kumpulan ide (konsep) yang dikomunikasikan dan dimaterialisasikan, dalam hal ini berwujud bahasa rupa.

Uang ORI 75 (tujuhpuluh lima) Rupiah, menggunakan gambar utama pande besi. Pande besi secara khusus memiliki kedudukan penting dalam masyarakat Jawa karena dianggap memiliki kesaktian dan tidak sembarang atau setiap orang dapat menjadi empu. (Lombard, 2002: 132) Sisa peradaban pande besi tersebut, di Yogyakarta kini dijumpai di 2 (dua) tempat, yaitu yang sekarang menjadi nama kampung Gamelan di timur Kraton Yogyakarta dan kampung Pandean Kotagede di tenggara Kraton Yogyakarta (Menurut Soedarisman Poerwokoesoemo mantan Walikota kedua kota Yogyakarta, bahwa sebutan kampung-kampung di dalam kota Yogyakarta yang tertua, adalah kampung yang namanya mempunyai hubungan langsung dengan resimen-resimen atau bagianbagiannya atau kampung yang namanya merupakan ahli-ahli tehnik, karena cara memberikan nama pada kampung-kampung itu, menurut nama pembesar atau golongan anak bauh angkatan perang, atau golongan-golongan ahli tehnik yang menempatinya semula. Lebih tegas umpamanya: Kampung Bintaran, karena yang semula menempatinya adalah Pangeran Bintoro; Kampung Surokarsan, karena semula menjadi tempat Prajurit
Surokarso; kampung Notoprajan, karena semula ditempati Pangeran Notoprojo; Kampung Dagen, karena semula ditempati oleh golongan undagi (Tukang kayu). Kampung Kumendaman, karena ditempati oleh Komandan Angkatan Perang; Kampung Wirogunan, karena ditempati oleh Bupati Wiroguno; Kampung Wirobrajan, karena semual ditempati oleh Prajurit Wirobrojo, dan seterusnya). Di kampung Gamelan, dahulu menjadi tempat para abdi dalem kraton membuat perkakas kuda (gamel dalam bahasa Jawa) seperti sepatu besi untuk kuda: ladam dan besi kekang gigi kuda: sanggurdi. Adapun kampung Pandean dahulu merupakan tempat para abdi dalem membuat peralatan senjata seperti keris dan pedang yang hebat untuk pusaka kraton Gambar aktivitas kerja pande besi, merupakan salah satu presentasi/gambaran kondisi sosial Yogyakarta saat itu. Sebagai seniman yang tinggal di kampung Rotowijayan wilayah Kraton Yogyakarta, Dibyo Pramudjo mengalami sendiri pasang surutnya perekonomian di masa revolusi fisik, sektor pekerjaan yang berbasis kerakyatan menjadi salah satu kegiatan di masyarakat yang mampu bertahan dan menjadi penyangga ekonomi Yogyakarta. Ikon yang muncul dari gambar Soekarno mengenakan jas dan peci ialah untuk menunjukan bahwa Soekarno seorang nasionalis. (Lombard, 2002: 158) Hal ini pernah disampaikan Soekarno kepada Cindy Adams (1966:51) bahwa pemakaian peci itu pun menjadi simbol dari gerakan nasionalisme: "Peci merupakan ciri khasku dan menjadi simbol bangsa Indonesia 
yang merdeka”.

Untuk menggambarkan kepribadian Soekarno itulah, maka Dibyo Pramudjo merepresentasikan simbolisme tersebut dengan menyajikan gambar potret (ikon) Sukarno secara realis figuratif, dan teknik arsir gores (dry point), sebuah metode penyajian yang oleh Feldman dikatakan an objective accuracy, tepat dan memenuhi fungsinya sekaligus an attemp to create pleasing forms, suatu kegiatan menciptakan bentuk yang dapat memberikan kepuasan dan keindahan. (Read, 1972: 18)

\section{Penutup}

Seperti telah tertuang dalam rumusan masalah, sejalan dengan tujuan yang telah ditetapkan dalam penelitian ini, maka dapat disimpulkan bahwa: pertama, gambar budaya tradisi diaplikasikan untuk menunjukkan identitas keindonesiaan. Kedua, menjadi simbol yang berhubungan dengan tempat atau lokasi disahkannya uang ORI terkait aktivitas budaya lokal (local activity) uang ORI dibuat. Ketiga, elemen bahasa rupa uang ORI menyiratkan kondisi faktual ideologis-sosiologis situasi zamannya. Adapun makna simbolis dari bahasa rupa uang ORI ialah mengomunikasikan bahwa Republik Indonesia adalah negara yang baru merdeka, berkedaulatan di seluruh aspek bidangnya, baik bangsa, negara maupun budayanya.

Pengkajian melalui pendekatan ikonografis dengan topik gambar utama uang kertas, pada dasarnya merupakan telaah bahasa rupa dalam perspektif disain grafis dan dimensi kultural historis. Melalui penelitian ini pula diketahui peran besar perancang uang ORI, dalam memahami tema dan konsep yang diberikan negara serta menuangkannya kedalam karya rupa uang kertas ORI. Bahasa rupa ORI tidak saja semata-mata hasil kontemplasi sebagai seniman murni, akan tetapi sekaligus menunjukkan kemampuannya dalam mengapresiasi dan mempresentasikan kondisi faktual masanya ke dalam karya rupa uang ORI, sebagai tanggung jawab artistik yang bersifat kritis dan mampu membawa insight sebagai penanda zaman. 


\section{Kepustakaan}

Adams, Cindy dalam Abdul Barsalim (terj). Soekarno Penyambung Lidah Rakyat, Gunung Agung, Jakarta.(1966)

Barzun, Jacques dan Henry F. Graff (1970) The Modern Researcher, Harcourt, Brace \& World. Inc., New York

Damianus, Komas, WT. (2005) Form Dalam Estetika, dalam Teks-teks Kunci Estetika Filsafat Seni, , Galang Press, Yogyakarta

Dahana ( 2003) Bangga Dipercaya Mencetak Uang ORI, Dalam Buku Kenangan Delapan Puluh Tahun Kanisius, Kanisius, Yogyakarta

Fitrianti, Rahmawati (2008) Perjalanan Panjang ORI, Mata Uang Yang Lahir Sebagai Alat Revolusi, Rosdakarya, Bandung.

Garraghan, Gilbert J (1957). A Guide to Historical Method, Fordham University Press, New York

Harsrinuksmo, Bambang (2004), Ensiklopedi Keris, Gramedia Pustaka Utama, Jakarta

Kahin, George Mc (1999)., Nasionalisme dan Revolusi Indonesia, Sinar Harapan dan UNS Press, Surakarta

Krisnadi, T. (2007), Sejarah Uang, Bandung, PT. Remaja Rosdakarya,

Lombard, Denys (2005), Nusa Jawa: Silang Budaya, Batas-Batas Pembaratan, Gramedia, Jakarta

Nurhajarini, Dwi Ratna (1999) Oeang Repoeblik Indonesia Peranannya dalam Perjuangan Bangsa 1946 - 1950.: BKSNT, Depdikbud, Yogyakarta

Panofsky, Erwin, (1979) Meaning in The Visual Arts, The University of Chicago Press, Chicago
Rader, Malvin (1973), A Modern Book of Aesthetics: An Antology, 4th edition, , Holt Rinehart and Winston, Inc., New York

Read, Herbert,(1972) The Meaning of Art, , Washington, Praeger Publ. Inc., New York

Sjamsudin, Helius (2007), Metodologi Sejarah, , Penerbit Ombak, Yogyakarta

Toekio, Soegeng (2007), Perupaan dan Pesan Denotatifnya, Bandung, Kelir,

Tabrani, Primadi (2005), Bahasa Rupa Gambar, Kelir, Bandung

Wiratsongko (1991) Yayasan SO 1 Maret, Bank Note \& Indonesian Coins:, Bank Tabungan Negara Indonesia, Jakarta

Wibawa, Prasida (2008), Pesona Tosan Aji, Gramedia, Jakarta,

Wolff. Janet (1993) The Social Production of Art, 2nd ed. University Press, New York

\section{Penerbitan Khusus}

Junus Kartiko Adinagoro, Toni, Mistikisme Keris Sorot - Majalah Gong, Edisi: 116/X/2009

Kusuma Widarti, Studi Disain Uang Kertas Indonesia Periode 1952 - 1983, Skripsi, Jurusan Seni Murni, Program Seni Grafik, FSRD, ISI Yogyakarta, 1986

Widagdo, Disain, Teori dan Praktik, "SENI" Jurnal Pengetahuan dan Penciptaan Seni, ISI Yogyakarta, III/03-Juli 1993

Surono, Tosan Aji dan Pembangunan Bangsa, Pengembangan Kebudayaan Jawa Tengah, Sasono Mulyo, Surakarta, 1979

Katalog 75 Tahun Kanisius, Penerbit Kanisius, Yogyakarta, 1998

\section{Web Site}

Irene Sarwindaningrum, Jiwa Kemerdekaan "Republik Jogja" Dukung RI blogspot.com, Kamis, 15 Januari 2009 